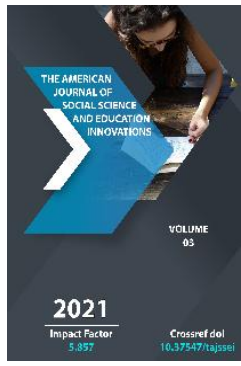

Journal Website: http://theamericanjour nals.com/index.php/taj ssei

Copyright: Original content from this work may be used under the terms of the creative commons attributes 4.0 licence.

\section{The Use Of Drama Techniques As An Effective Learning Tool In ELT}

\author{
Malika Kholiyor Kizi Khidirova \\ Student Of Karshi State University, Uzbekistan \\ Shakhnoza Burievna Nashirova \\ Supervisor Lecturer Of Karshi State University, Uzbekistan
}

\title{
ABSTRACT
}

Teaching a foreign language by means of drama techniques contributes to the social, emotional, and intellectual development of the student's personality. Also, drama techniques help to increase the motivation of both the student and the teacher. The teacher takes into account the needs and interests of students, has personal approaches to them. Each of the students develops according to their abilities. In the distribution of roles from the play, complex texts are distributed among students with a higher level of training, and simple roles among students with less training. This is not a reason to believe that someone showed better performance and someone played not well. Every role is counted. When a reciprocal feedback arises between the teacher and the student, the work will be more fruitful. Such a creative atmosphere allows the teacher to subtly and imperceptibly educate students, monitor their behavior, and correct it. Consequently, drama techniques creates such conditions when a student wants to listen to a foreign speech, speak a foreign language, when he is carried away and feels a sense of satisfaction from what he is doing and what he can do in a foreign language. The article discusses of use of the drama techniques in teaching English, which acts as an effective means of teaching the language and increasing motivation.

\section{KEYWORDS}


Foreign language teaching, methodology, motivation, drama techniques, students, dramatization, role play, communication

\section{INTRODUCTION}

Nowadays, many parents want their child to start learning English at school or even in kindergarten, which is not surprising, since English is one of the most spoken languages in the world. The sooner child start learning a foreign language, the more naturally and better it will be learned along with his/her native language. Learning a foreign language is psychologically hard work for both a student and an adult. Modern methodology of teaching a foreign language is focused on the formation of motivation, learning expressions used in communication. Education should be organized in such a way that the child gains knowledge, and not just memorizes the information that was prepared in advance.

\section{MATERIALS AND METHODS}

Currently, the main goal of teaching English at school is to teach students to communicate in English. In our opinion, the main positive feature of using the elements of drama techniques in foreign language lessons is the possibility of free communication in a foreign language. Motivation determines the quality of learning and the pace is one of the main criteria of the learning process. Motive translated from Latin means to carry out movement. According to Flemming, All our ideas, all searches and constructions turn to dust if the student has no desire to learn [5]. The use of drama in teaching a foreign language to schoolchildren of different ages has the following goals:

$>$ Formation of primary communication skills in a foreign language in children;
$>$ Ability to use a foreign language to achieve their goals, express thoughts and feelings, in real-life communication situations;

Education of an active - creative and emotional - aesthetic attitude to the word through the preparation and staging of performances [2].

The word "drama" comes from Greek, meaning "action" or "a play". "Drama" is not an easy term to define. It is often confused with "theatre". Researchers compare it with a blanket term covering "a wide range of oral activities that have an element of creativity present" [3], but above "all it should be a communicative activity where the student makes the choice" [1]. In this regard, the teacher sets the tasks of "immersing children in the atmosphere of the theatre, while developing their speech and cognitive abilities", relying on speech experience, both in their native language and in a foreign language, to create a positive attitude towards the further study of foreign languages, to awaken interest in life and the culture of other countries [7].

The formation of positive motivation should be considered by the teacher as a special task. As a rule, motives are associated with the cognitive interests of students, the need to master new knowledge, skills, and abilities. But the first and natural need of foreign language learners is communication. To organize a favorable climate that orientates students towards communication, it is 
necessary to choose such forms of lesson that will stimulate the activities of students. In our opinion, one of such techniques, which meet the tasks of modern teaching foreign languages, is the use of drama techniques in the classroom. Dramatization is a methodological technique that involves the introduction of pre-prepared elements of theatrical action into a lesson, design, in which pre-prepared students appear in the classroom with elements of the hero's costume, utter his most expressive remarks. Dramatization as an element of theatrical art is close and understandable to children, because the theater is based on play, and it itself is one of the types of play activity and the leading activity of children. The theatre has the necessary potential for the aesthetic development of children, namely, it contributes to the development of their emotional memory, imagination, etc. The theater takes into account the specifics of children's perception, guides the child's fantasy, helps his development and grows into creative imagination. Elements of theatrical art provide an opportunity to perceive educational material not only rationally, but also emotionally.

In the process of learning a foreign language, dramatization is encountered at every step: any vocabulary, any colloquial forms are practiced not only in monologue speech, but also in dialogues. Students communicate in English on a given topic, often create their own dialogues using keywords, and there is an element of dramatization in all of these exercises. Such a serious obstacle as the "language barrier" becomes easily surmountable as soon as students find themselves in a situation of play, role-based interaction, and become involved in the general creative process. During the preparation of the play, the dramatic method allows you to productively work on vocabulary, grammar, pronunciation and intonation.

Dramatization can be of different levels:

- Animation of the illustration. Through external factors, through the form, understand what feelings the heroes experience;

- An improvisation game based on a plot picture: "Try to find a way out of this scene, predict the further development of the plot";

- Staging group and individual live pictures, pantomime;

- Utterance of individual lines of the hero with the installation of not only intonation, but also plastic expressiveness;

- Reading for heroes where it is said about heroes. The child needs to put himself in the place of the hero, get used to the image, try to speak and act for him;

- Staging a performance. The highest level of dramatization. The result is possible only with the active involvement of each child in the creation of the performance.

Dramatization is one of the effective methods of interactive learning. It ensures the assimilation of new lexical material and creates an emotionally positive attitude in learning. In fact, dramatization can be seen as a form of role play, in which each participant has the opportunity to express themselves. 
The principle of the functionality of teaching a foreign language is embodied in the method of performing drama in the form of a roleplaying game. The process of foreign language communication is a model of real communication. The student understands that he can give him practical mastery of a foreign language.

When selecting lexical material, we are guided by the following principles: accessibility; involving reading the maximum number of students per group; students' interest in dramatization (humorous stories).

This form of learning English develops and improves speech and thinking activity, contributes to the emergence of a sincere desire to communicate in a foreign language, not only in class, but also at inopportune hours. In other words, an internal motive for the study of the discipline is successfully formed here [6].

Lessons with the use of drama are usually held lively, emotionally, with the activity of students in a favorable psychological atmosphere. For example, when studying the topic of "protecting the environment," we can suggest (as a project) to prepare a "meeting" for the topic "Celebrities" - an Oscar ceremony, and so on. Emphasizing the importance of using dramatization as a method of teaching all academic subjects, it should be noted the importance of using this technique in foreign language lessons in order to form the basic universal educational actions of students: personal, regulatory, cognitive and communicative. The use of dramatization in foreign language lessons improves the pronunciation skills of students, provides the creation of a communicative-catalytic, cognitive and aesthetic motivation. Preparing a performance is a creative work that contributes to the development of children's language communication skills and the disclosure of their individual creative abilities. This type of work activates the thinking and speech activity of students, develops their interest in literature, serves to better assimilate the culture of the country of the target language, and also deepens the knowledge of the language, since the process of memorizing vocabulary takes place. Along with the formation of an active vocabulary of schoolchildren, a so-called passive-potential vocabulary is being formed. And it is important that students get satisfaction from this type of work.

Each teacher should have little inventions and secrets on how to increase the motivation of students in learning a foreign language, how to develop their creativity and speech activity through using a variety of techniques stimulating students' interest, helping them learn and learn new and unknown.

It can be assumed that the method of drama techniques is so named because of its proximity to theatrical performance, namely, to one of the main elements of theatrical art drama. "Drama most deeply and adequately embodies in art the forms and methods of human communication as a specific and unique form of human existence" [4]. The teacher must ensure that not only selected and talented schoolchildren take part in the staging and staging of plays, but also all children of a given age group. Collective improvisation, mass character, collective work on the stage should serve as a method of forming a "social person" in a child, a method for the birth of a new art. In such situations, 
drama techniques help children "plunge into the language", and make it possible to overcome the speech barrier.

Teachers who use the technique of drama techniques note that their students have an increased level of motivation to learn a foreign language at different stages, as well as their self-esteem. This method allows to get rid of constraint and embarrassment, from the fear of making a mistake.

\section{CONCLUSION}

We can conclude that teaching a foreign language by means of drama techniques contributes to the social, emotional, and intellectual development of the child's personality. Also, drama techniques help to increase the motivation of both the student and the teacher. The teacher takes into account the needs and interests of students, has a personal approach to them. Each of the students develops according to their abilities. In the distribution of roles from the play, complex texts are distributed among students with a higher level of training, and simple roles among students with less training. But this is not a reason to believe that someone is better and someone is worse. Every role counts. When a reciprocal feedback arises between the teacher and the student, the work will be more fruitful. Such a creative atmosphere allows the teacher to subtly and imperceptibly educate students, monitor their behavior, and correct it. Consequently, drama techniques creates such conditions when a child wants to listen to a foreign speech, speak a foreign language, when he is carried away and feels a sense of satisfaction from what he is doing and what he can do in a foreign language.

\section{REFERENCES}

1. Billikova A., Kissova M. Drama Techniques in the Foreign Language Classroom. London, Nitra, 2013.

2. Davies P. The Use of Drama in English Language Teaching. TESL Canada Journal Revue, TESL DU, 1990.

3. Dodson S.L. The Educational Purpose of Drama for ESL. G. Brauer Iginde, Body and Language: Intercultural Learning Through Drama. Greenwood, 2002, pp. 161-175.

4. Dougill J. Drama Activities for Language Learning. London, Macmillan Publishers, 1994.

5. Fleming $M$. "Drama" in Byram. M. (ed.) Encyclopedia of Language Teaching and Learning. London, Nitra, 2013.

6. Fleming $M$. Starting Drama Teaching. London, David Fulton Publishers, 2003.

7. Via R. Drama \& Self in Language Learning. The English Teaching Forum, 1985, pp.12-15.

8. Way B. Development Through Drama. London, Longman, 1967. 